\title{
A systematic review and meta-analysis of effectiveness and safety of therapy for overactive bladder using botulinum toxin A at different dosages
}

\author{
Hui-Yun Gu${ }^{1, *}$, Ju-Kun Song ${ }^{2,}{ }^{*}$, Wen-Jun Zhang ${ }^{3}$, Jin Xie ${ }^{4}$, Qi-Sheng Yao ${ }^{5}$, Wen-Jing \\ Zeng ${ }^{6}$, Chao Zhang ${ }^{1}$ and Yu-Ming Niu, ${ }^{1,5}$ \\ ${ }^{1}$ Center for Evidence-Based Medicine and Clinical Research, Taihe Hospital, Hubei University of Medicine, Shiyan 442000, China \\ ${ }^{2}$ Department of Oral and Maxillary Surgery, Guizhou Provincial People's Hospital, Guiyang 550002, China \\ ${ }^{3}$ Department of Ultrasound, Taihe Hospital, Hubei University of Medicine, Shiyan 442000, China \\ ${ }^{4}$ Administrative Office, Taihe Hospital, Hubei University of Medicine, Shiyan 442000, China \\ ${ }^{5}$ Department of Urinary Surgery, Taihe Hospital, Hubei University of Medicine, Shiyan 442000, China \\ ${ }^{6}$ Department of Anesthesiology, Taihe Hospital, Hubei University of Medicine, Shiyan 442000, China \\ * Co first authors
}

Correspondence to: Chao Zhang, email: zhangchao0803@126.com

Yu-Ming Niu, email: niuyuming@yeah.net

Keywords: overactive bladder, botulinum toxin A, urinary incontinence, incontinence quality of life, meta-analysis

Received: June 04, 2017 Accepted: July 25, $2017 \quad$ Published: August 07, 2017

Copyright: Gu et al. This is an open-access article distributed under the terms of the Creative Commons Attribution License 3.0 (CC BY 3.0 ), which permits unrestricted use, distribution, and reproduction in any medium, provided the original author and source are credited.

\section{ABSTRACT}

Purpose: To assess the effectiveness and safety of botulinum toxin A (BTX-A) at different dosages for overactive bladder (OAB).

Materials and Methods: The MEDLINE, EMBASE, and Cochrane Controlled Trials Register databases were searched through November 3, 2016 to identify relevant randomized controlled trials (RCTs).

Results: Eleven studies were identified in this meta-analysis. Compared with placebo, the urinary incontinence (UI) episodes per week as the primary outcomes, urodynamic parameters including maximum cystometric capacity (MCC), and maximum detrusor pressure (MDP) for neurogenic detrusor overactivity (NDO) at 6 weeks, and for idiopathic detrusor overactivity (IDO) at $\mathbf{3 6}$ weeks were evaluated. These and other outcomes for effectiveness of BTX-A at different dosages in two observation periods indicate that a dose greater than $\mathbf{5 0} \mathbf{U}$ is significantly more effective for certain symptoms of OAB compared with placebo. However, there were no significant differences between some dosages. Compared with placebo, the outcomes of total adverse events for NDO and for IDO show that doses of $\mathbf{3 0 0} \mathrm{U}$ and $200 \mathrm{U}$ for NDO are associated with more complications.

Conclusions: In consideration that the treatments of BTX-A were with minimal, local, and manageable adverse effects, this meta-analysis demonstrates that BTX-A $200 \mathrm{U}$ is recommended for management of NDO for short-term treatment for there was no significant difference from the larger dose of $300 \mathrm{U}$. The short-term efficacies of BTX-A for IDO remain to be investigated.

\section{INTRODUCTION}

Overactive bladder $(\mathrm{OAB})$ is a multifactorial and chronic disease with lower urinary tract symptoms, and is defined by the International Continence Society as urgency with or without urge urinary incontinence, usually accompanied by frequency and nocturia, but not caused by urinary tract infection (UTI) [1]. The prevalence of OAB is approximately $12-19 \%$ in both men and women [2], and has a detrimental effect on the quality of life and social 
functioning [3]. OAB includes detrusor instability and detrusor hyperreflexia, with a relatively high incidence of neurogenic detrusor overactivity (NDO) due to spinal cord injury (SCI) or other neurologic conditions such as multiple sclerosis (MS) [4]. Idiopathic detrusor overactivity (IDO) is another common type of OAB. OAB can lead to urinary incontinence and frequency and changes in urodynamic parameters including bladder capacity, compliance, and other important functions [5, 6]. Current first-line treatment for $\mathrm{OAB}$ is antimuscarinic medicine [7]. However, longterm antimuscarinic treatment is suboptimal, because of inadequate effectiveness and bothersome side effects [8, 9].

Botulinum toxin A (BTX-A) produced by Clostridium botulinum is a potential alternative. BTX-A is a neuromodulator that inhibits the release of acetylcholine and other neurotransmitters by binding to synaptic vesicle glycoprotein $2 \mathrm{~A}$ and reduces muscle spasticity [10, 11]. The use of BTX-A for NDO was first reported by Schurch [12], and Smith [13] investigated its effect in an animal model. Based on its mechanism and subsequent studies, BTX-A became a second line medicine for NDO, as recommended by a European consensus report [14] and the Food and Drug Administration.

Several relevant meta-analyses [15-21] had been conducted for NDO. In these meta-analyses, some studies compared different dosages of BTX-A with placebo at only one time point after BTX-A injection [15, 20, 21], while others compared pooled dosages with placebo [16, 17]; however, there was a lack of comprehensive analysis and consideration of the influence of the dosages on effectiveness outcomes. One meta-analysis [19] compared the grouped data of the same outcome indicators at different time points, which could produce errors and interfere with correct conclusions, thus reducing the reliability and value of the study. For IDO, although, sacral neuromodulation is the approved second-line treatment [22] and the effectiveness of BTX-A for IDO has been demonstrated in a number of uncontrolled studies [23-29] and in small Randomized controlled trials (RCTs) [30, 31], the effectiveness and safety is still under evaluation. To resolve these questions about effectiveness and safety, this study will examine outcomes using different dosages of BTX-A for NDO and IDO, and will evaluate the evidence for optimal doses in the clinical management of NDO and IDO.

\section{RESULTS}

\section{Study selection and characteristics of individual studies}

A total of 1,418 studies were initially identified for use in our meta-analysis. Of these, 203 were excluded as duplicates. Of the remaining 1,215 potential articles, 1,131 were excluded by reading titles and abstracts, and the full texts of 84 articles were independently read by two authors. Eventually, 11 articles [22, 32-41] were included in our meta-analysis (Figure 1). The characteristics of the individual study are presented in Table 1.

\section{Quality of the individual studies}

The results of the risk of bias assessment are shown in Table 2. Eleven RCTs included in this meta-analysis were characterized as high quality studies.

\section{Effectiveness}

\section{Urinary incontinence (UI) episodes per week}

\section{UI episodes per week of NDO based on short-term observation at 2 weeks}

One RCT [33] comprised BTX-A groups (200 U and $300 \mathrm{U}$ ) and a placebo group was identified and included to evaluate outcomes at 2 weeks. Compared with placebo in a fixed-effects model, Figure 2 show that BTX-A 200 $\mathrm{U}$ for NDO significantly reduced UI episodes per week (weighted mean difference (WMD): -9.10, 95\% confidence interval (CI): -14.10 to $-4.10, I^{2}=$ Not available (NA), $P=\mathrm{NA}$ ), but the result for $300 \mathrm{U}$ vs. placebo showed no significant reduction in UI episodes per week of NDO (WMD: $-6.10,95 \% \mathrm{CI}:-12.54$ to $0.34, I^{2}=\mathrm{NA}, P=\mathrm{NA}$ ). However, there were no differences between BTX-A 300 $\mathrm{U}$ and $200 \mathrm{U}$ in the fixed-effects model (WMD: 3.00, 95\% CI: -3.30 to $9.30, I^{2}=\mathrm{NA}, P=\mathrm{NA}$ ).

\section{UI episodes per week of NDO based on short-term observation at 6 weeks}

Four studies [33, 36, 37, 39] comprised of BTX-A groups (200 U and $300 \mathrm{U}$ ) and a placebo group were identified and included to evaluate the outcomes at 6 weeks. Figure 3 show significant reductions in UI episodes per week of NDO (BTX-A $300 \mathrm{U}$ vs. placebo, WMD: -11.42 , 95\% CI: -13.91 to $-8.93, I^{2}=50.0 \%$, $P=0.135$; BTX-A $200 \mathrm{U}$ vs. placebo, WMD: $-10.72,95 \%$ CI: -13.40 to $\left.-8.04, I^{2}=0.0 \%, P=0.626\right)$. However, the differences between $300 \mathrm{U}$ and $200 \mathrm{U}$ at 6 weeks were not statistically significant in the fixed-effects model (WMD: $-0.38,95 \%$ CI: -2.60 to $\left.1.84, I^{2}=0.0 \%, P=0.765\right)$.

\section{UI episodes per week of NDO based on short- term observation at 12 weeks}

One RCT [33] with data for UI episodes per week at 12 weeks was evaluated. Figure 4 show significant reductions in UI episodes per week of NDO in both 200 $\mathrm{U}$ and $300 \mathrm{U}$ BTX-A groups compared with placebo at 12 weeks (WMD: $-8.50,95 \% \mathrm{CI}:-14.46$ to $-2.54, I^{2}=\mathrm{NA}$, $P=\mathrm{NA}$; WMD: $-7.80,95 \% \mathrm{CI}:-13.73$ to $-1.87, I^{2}=\mathrm{NA}$, $P=$ NA, respectively.). The outcome of subgroup analysis showed no significant differences between the BTX-A groups (WMD: $0.70,95 \% \mathrm{CI}:-4.73$ to $6.13, I^{2}=\mathrm{NA}$, $P=\mathrm{NA})$. 
Table 1: Characteristics of individual study

\begin{tabular}{|c|c|c|c|c|c|c|c|c|c|}
\hline First(author) & Year & Region & $\begin{array}{l}\text { No.of patiens } \\
\text { (female) }\end{array}$ & $\begin{array}{l}\text { Ages mean } \\
\text { (SD) }\end{array}$ & Design & $\begin{array}{c}\text { Classification } \\
\text { of urinary } \\
\text { incontinence }\end{array}$ & $\begin{array}{c}\text { Basic } \\
\text { diseases }\end{array}$ & Intervention & $\begin{array}{l}\text { Follow-up } \\
\text { (weeks) }\end{array}$ \\
\hline Schurch [41] & 2005 & Switzerland & $59(23)$ & 41 & $\begin{array}{l}\text { Randomized, } \\
\text { doubled-blind }\end{array}$ & NDO & $\begin{array}{l}\text { MS:6, } \\
\text { SCI:53 }\end{array}$ & $\begin{array}{l}\text { Group 1: BTX-A 300U (19) } \\
\text { Group 2: BTX-A 200U (19) } \\
\text { Group 3: Placebo (21) }\end{array}$ & 6 \\
\hline Dmochowski [34] & 2010 & USA & $313(288)$ & 58.8 & $\begin{array}{l}\text { Randomized, } \\
\text { doubled-blind }\end{array}$ & IOAB & NA & $\begin{array}{l}\text { Group 1: BTX-A 50U (56) } \\
\text { Group 2: BTX-A 100U (55) } \\
\text { Group 3: BTX-A 150U (50) } \\
\text { Group 4: BTX-A 200U (52) } \\
\text { Group 5: BTX-A 300U(55) } \\
\text { Group 6: Placebo (43) }\end{array}$ & NA \\
\hline Cruz [33] & 2011 & Portugal & $275(155)$ & $\begin{array}{c}46(13.1) \\
44.4(13.9) \\
46.9(13.4)\end{array}$ & $\begin{array}{l}\text { Randomized, } \\
\text { doubled-blind }\end{array}$ & NDO & $\begin{array}{l}\text { MS: } 154, \\
\text { SCI: } 121\end{array}$ & $\begin{array}{l}\text { Group 1: BTX-A 200U(92) } \\
\text { Group 2: BTX-A 300U(91) } \\
\text { Group 3: Placebo (92) }\end{array}$ & $2,6,12$ \\
\hline Rovner [40] & 2011 & USA & $313(288)$ & 58.8 & $\begin{array}{l}\text { Randomized, } \\
\text { doubled-blind }\end{array}$ & IOAB & NA & $\begin{array}{l}\text { Group 1: BTX-A 50U(57) } \\
\text { Group 2: BTX-A 100U(54) } \\
\text { Group 3: BTX-A 150U(49) } \\
\text { Group 4: BTX-A 200U(53) } \\
\text { Group 5: BTX-A 300U(56) } \\
\text { Group 6: Placebo (44) }\end{array}$ & 12,36 \\
\hline Denys [22] & 2012 & France & $199(87)$ & $62.3,61.7$ & $\begin{array}{l}\text { Randomized, } \\
\text { doubled-blind }\end{array}$ & IOAB & NA & $\begin{array}{l}\text { Group 1: BTX-A 50U(23) } \\
\text { Group 2: BTX-A 100U(23) } \\
\text { Group 3: BTX-A 150U(30) } \\
\text { Group 4: Placebo (31) }\end{array}$ & 12 \\
\hline Ginsberg [36] & 2012 & USA & $416(245)$ & $46(13)$ & $\begin{array}{l}\text { Randomized, } \\
\text { doubled-blind }\end{array}$ & NDO & $\begin{array}{l}\text { MS:227, } \\
\text { SCI: } 189\end{array}$ & $\begin{array}{l}\text { Group 1: BTX-A200U(135) } \\
\text { Group 2: BTX-A300U(127) } \\
\text { Group 3: Placebo (145) }\end{array}$ & 6 \\
\hline Ginsberg [35] & 2013 & USA & $381(311)$ & $\begin{array}{l}49.7(12.1) \\
49.9(10.7) \\
50.2(10.7)\end{array}$ & $\begin{array}{l}\text { Randomized, } \\
\text { doubled-blind }\end{array}$ & NDO & $\begin{array}{l}\text { MS:381, } \\
\text { SCI:310 }\end{array}$ & $\begin{array}{l}\text { Group 1: BTX-A 200U(227) } \\
\text { Group 2: BTX-A 300U(223) } \\
\text { Group 3: Placebo (241) }\end{array}$ & 6 \\
\hline Nitti [38] & 2013 & USA & $557(497)$ & $\begin{array}{l}61.7(12.7) \\
61(13.1)\end{array}$ & $\begin{array}{l}\text { Randomized, } \\
\text { doubled-blind }\end{array}$ & IOAB & NA & $\begin{array}{l}\text { Group 1: BTX-A100U (278) } \\
\text { Group 2: Placebo (272) }\end{array}$ & 12 \\
\hline Rovner [39] & 2013 & USA & $691(400)$ & $\begin{array}{c}45.9,45.6 \\
46.2\end{array}$ & $\begin{array}{l}\text { Randomized, } \\
\text { doubled-blind }\end{array}$ & NDO & $\begin{array}{l}\text { MS: } 103 \\
\text { SCI: } 138\end{array}$ & $\begin{array}{l}\text { Group 1: BTX-A 200U(227) } \\
\text { Group 2: BTX-A 300U(223) } \\
\text { Group 3: Placebo (241) }\end{array}$ & 6 \\
\hline Kennelly [37] & 2013 & USA & 387 (233) & 46.4 & $\begin{array}{l}\text { Randomized, } \\
\text { doubled-blind }\end{array}$ & NDO & SCI, MS & $\begin{array}{l}\text { Group 1: BTX-A 300U(185) } \\
\text { Group 2: BTX-A 200U(202) }\end{array}$ & 6 \\
\hline Abdelwahab [32] & 2015 & Egypt & $80(63)$ & $\begin{array}{l}31.35 \\
30.22\end{array}$ & $\begin{array}{l}\text { Randomized, } \\
\text { doubled-blind }\end{array}$ & IOAB & NA & $\begin{array}{l}\text { Group 2: BoNTA 200U (40) } \\
\text { Group 1: BTX-A 100U (40) }\end{array}$ & 12,36 \\
\hline
\end{tabular}

NDO: Neurogenic detrusor overactivity, IDO: Idiopathic detrusor overactivity, MS: Multiple sclerosis, SCI: Spinal cord injury, BTX-A: Botulinum toxin A, NA: Not available.

\section{Maximum cystometric capacity (MCC)}

\section{MCC of NDO based on short-term observation at 6 weeks}

Five RCTs [33, 35, 36, 39, 41] reporting data for MCC were collected in our study. Figure 5 show statistically significant improvement in MCC of NDO at 6 weeks in a comparison of BTX-A $300 \mathrm{U}$ and $200 \mathrm{U}$ with placebo (WMD: 151.52, 95\% CI: 132.86 to170.18, $I^{2}=0.0 \%, P=0.990$; WMD: $141.45,95 \%$ CI: 123.57 to $159.33, I^{2}=0.0, P=0.991$, respectively). Significant improvements were not seen in a comparison of BTX-A 300 U vs. 200 U (WMD: 9.23, 95\% CI: -11.61 to 30.06 , $\left.I^{2}=0.0 \%, P=0.988\right)$.

\section{MCC of IDO based on short-term observation at 12 week}

Three RCTs $[22,32,40]$ using 5 different doses of BTX-A vs. placebo performed an analysis of MCC; the subgroup details are shown in Figure 6. Figure 6 show that significant improvement was only seen in subgroups of BTX-A $150 \mathrm{U}$ and $300 \mathrm{U}$ vs. placebo, BTX-A 150 $\mathrm{U}$ vs. $50 \mathrm{U}$, BTX-A $300 \mathrm{U}$ vs. $50 \mathrm{U}$, and BTX-A 300 $\mathrm{U}$ vs. $100 \mathrm{U}$ for IDO (WMD: 58.92, 95\% CI: 16.02 to $101.81, I^{2}=0.0 \%, P=0.715$; WMD: $81.30,95 \% \mathrm{CI}$ : 26.21 to $136.39, I^{2}=\mathrm{NA}, P=\mathrm{NA}$; WMD: $52.08,95 \%$ CI:12.93 to $91.22, I^{2}=0.0 \%, P=0.978$; WMD: 80.80 , $95 \%$ CI:34.74 to $126.86, I^{2}=\mathrm{NA}, P=\mathrm{NA}$; WMD: $59.80,95 \% \mathrm{CI}: 11.53$ to $\left.108.07, I^{2}=\mathrm{NA}, P=\mathrm{NA}\right)$. However, other subgroup results showed no statistical significance.

\section{MCC of IDO based on long-term observation at 36 weeks}

Two RCTs $[32,40]$ met the criteria. As shown in Figure 7, no subgroup results showed statistical significance in a fixed-effects model at 36 weeks. 
Table 2: Quality assessment of individual study

\begin{tabular}{|c|c|c|c|c|c|c|c|c|}
\hline Author & Year & $\begin{array}{c}\text { Random } \\
\text { sequence } \\
\text { generation }\end{array}$ & $\begin{array}{l}\text { Allocation } \\
\text { concealment }\end{array}$ & $\begin{array}{c}\text { Blinding of } \\
\text { participants and } \\
\text { personnel }\end{array}$ & $\begin{array}{l}\text { Blinding } \\
\text { of outcome } \\
\text { assessment }\end{array}$ & $\begin{array}{c}\text { Incomplete } \\
\text { outcome data }\end{array}$ & $\begin{array}{l}\text { Selective } \\
\text { reporting }\end{array}$ & Other \\
\hline Schurch [41] & 2005 & low & low & low & low & low & low & unclear \\
\hline Dmochowski [34] & 2010 & low & unclear & low & low & low & low & unclear \\
\hline Cruz [33] & 2011 & low & low & low & low & low & low & unclear \\
\hline Rovner [40] & 2011 & low & low & unclear & low & low & low & unclear \\
\hline Denys [22] & 2012 & low & unclear & low & low & low & low & unclear \\
\hline Ginsberg [36] & 2012 & low & low & low & low & low & low & unclear \\
\hline Ginsberg [35] & 2013 & low & low & low & low & low & low & unclear \\
\hline Nitti [38] & 2013 & low & low & unclear & low & low & low & unclear \\
\hline Rovner [39] & 2013 & low & low & low & low & low & low & unclear \\
\hline Kennelly [37] & 2013 & low & low & low & low & low & low & unclear \\
\hline Abdelwahab [32] & 2015 & low & unclear & low & low & low & low & unclear \\
\hline
\end{tabular}

\section{The volume per void}

The volume per void of NDO based on short-term observation at 2 weeks

One RCT [33] was included for the volume per void. As shown in Supplementary Table 1, it is clear that both BTX-A $300 \mathrm{U}$ and $200 \mathrm{U}$ for NDO were superior to placebo at 2 weeks in the fixed-effects model (BTX-A 300 U vs. placebo, WMD: $49.90,95 \%$ CI: 17.54 to $82.26, I^{2}$ $=$ NA, $P=$ NA; BTX-A 200 U vs. placebo, WMD: 42.60, $95 \%$ CI: 14.49 to $\left.70.71, I^{2}=\mathrm{NA}, P=\mathrm{NA}\right)$. Nevertheless, significant differences were not observed at 2 weeks between $300 \mathrm{U}$ and $200 \mathrm{U}$ (WMD: 7.30, 95\% CI: -30.28 to $\left.44.88, I^{2}=\mathrm{NA}, P=\mathrm{NA}\right)$.

The volume per void of NDO based on short-term observation at 6 weeks

Three RCTs [33, 37, 39] were included for the volume per void. As shown in Supplementary Table 1, it is clear that both BTX-A $300 \mathrm{U}$ and 200 $\mathrm{U}$ for NDO were superior to placebo at 6 weeks in the fixed-effects model (BTX-A $300 \mathrm{U}$ vs. placebo, WMD: $100.73,95 \%$ CI: 83.24 to 118.22 , $I^{2}=0.0 \%, P=0.328$; BTX-A $200 \mathrm{U}$ vs. placebo, WMD: $92.68,95 \%$ CI: 76.22 to $109.14, I^{2}=0.0 \%$,

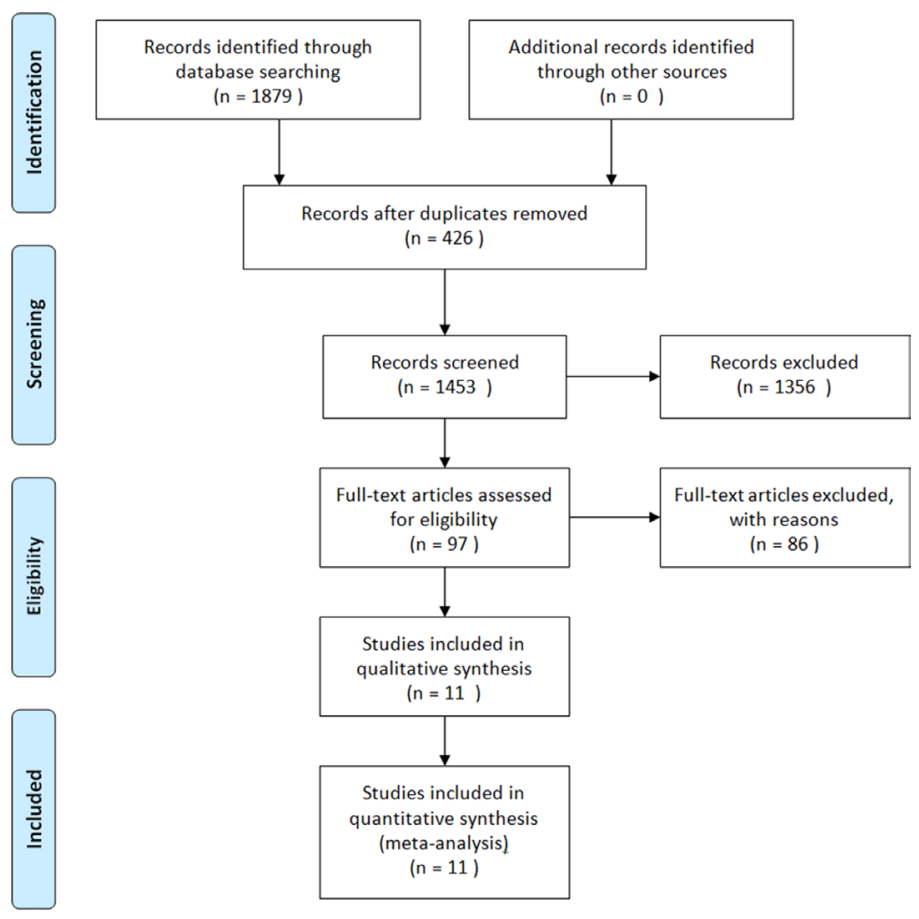

Figure 1: A flow diagram of the study selection process. 
$P=0.982)$. Nevertheless, significant differences were not observed at 6 weeks between $300 \mathrm{U}$ and $200 \mathrm{U}$ (WMD: $4.72,95 \% \mathrm{CI}:-12.12$ to $\left.21.57, I^{2}=0.0 \%, P=0.663\right)$.

The volume per void of NDO and IDO based on shortterm observation at 12 weeks

Three RCTs $[22,33,38]$ were included for analysis of the volume per void. In accordance with doses of BTX-A and the types of OAB, 9 subgroup analyses were conducted using a fixed-effects model (BTX-A $100 \mathrm{U}$ vs. placebo, $P^{2}=42.0 \%$,
$P=0.189$; others, $P=\mathrm{NA}, P=\mathrm{NA})$. Supplementary Tables 1 and 2 show significant improvement in the volume per void for BTX-A $100 \mathrm{U}, 150 \mathrm{U}$ for IDO, $200 \mathrm{U}, 300 \mathrm{U}$ for NDO compared with placebo, and for $100 \mathrm{U}$ vs. $50 \mathrm{U}$ for IDO (WMD: 34.48, 95\% CI: 16.73 to $52.23, P^{2}=42.0 \%, P=0.189$; WMD: $81.00,95 \%$ CI: 7.98 to $154.02, I^{2}=\mathrm{NA}, P=\mathrm{NA}$; WMD: 83.70 , 95\% CI: 54.54 to $112.86, P^{2}=\mathrm{NA}, P=\mathrm{NA}$; WMD: $78.80,95 \%$ CI: 46.23 to $111.37, P^{2}=\mathrm{NA}, P=\mathrm{NA}$; WMD: $34.40,95 \%$ CI: 3.79 to $65.01, P^{2}=\mathrm{NA}, P=\mathrm{NA}$, respectively). The other subgroups showed no significant results.

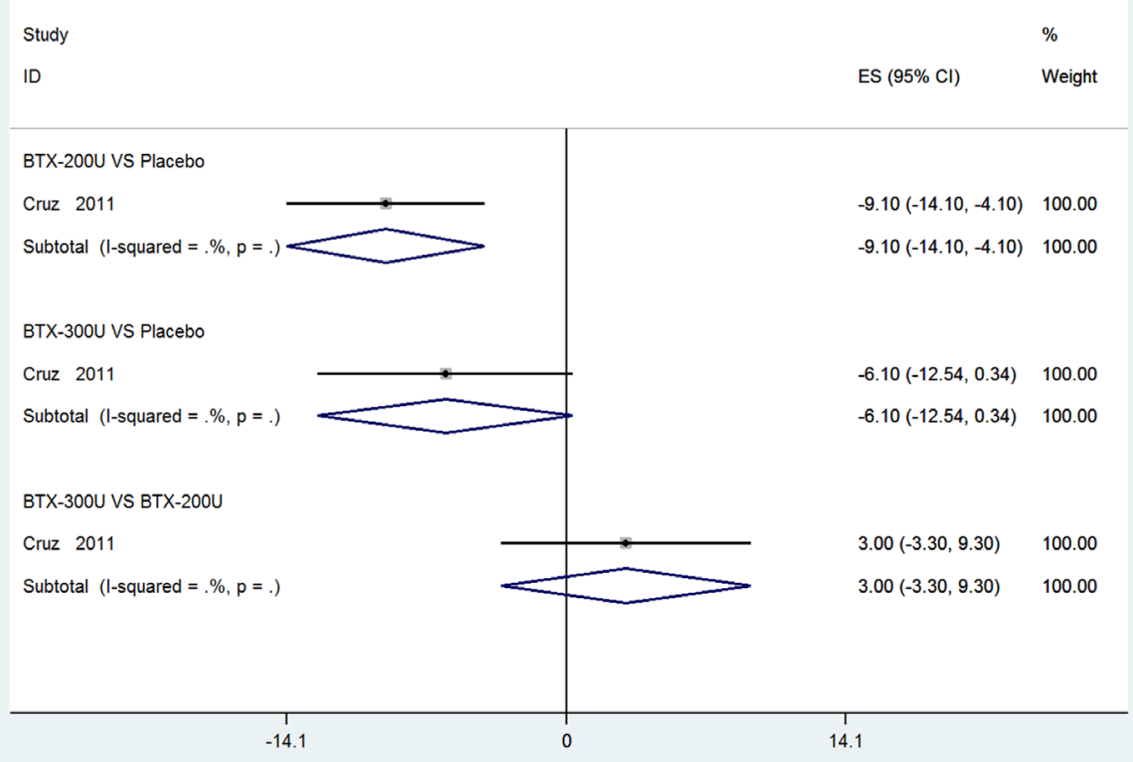

Figure 2: Forest plot of the changes of UI episodes per week of NDO at 2 weeks.

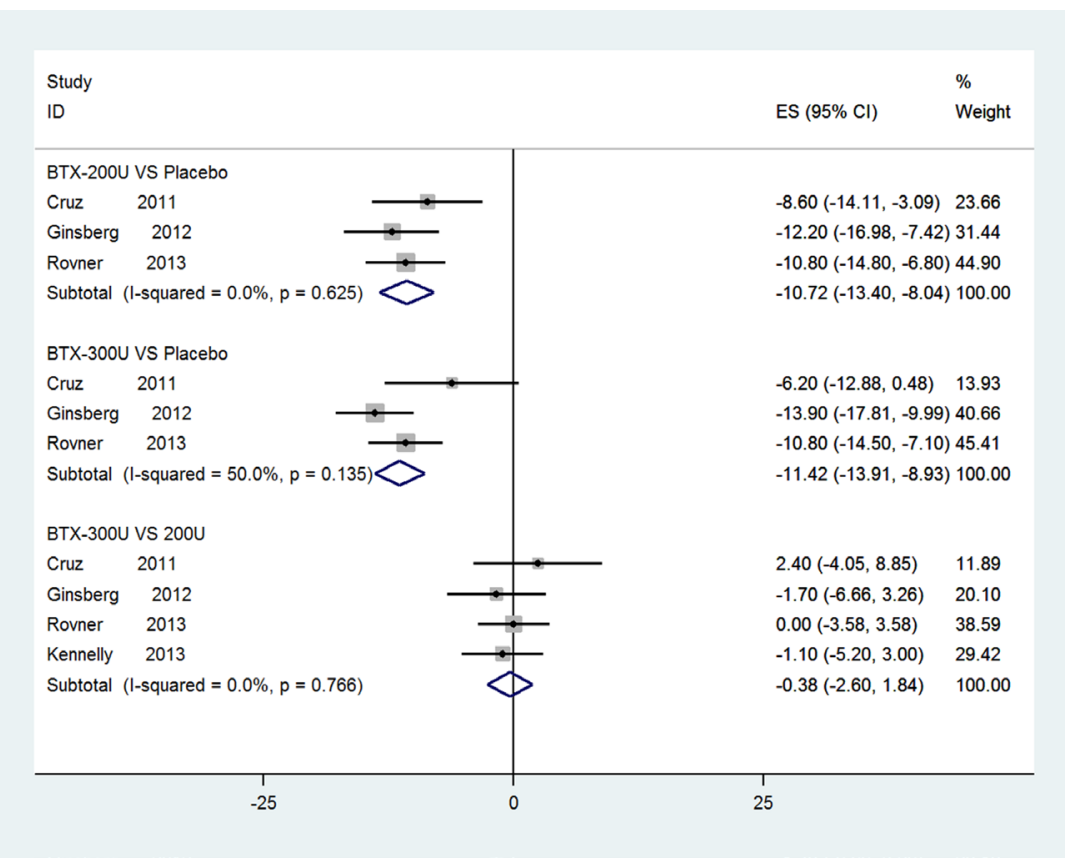

Figure 3: Forest plot of the changes of UI episodes per week of NDO at 6 weeks. 


\section{Maximum detrusor pressure (MDP)}

\section{MDP of NDO based on short-term observation at 6 weeks}

Five RCTs [33, 35, 36, 39, 41] included MDP data, generating 3 subgroups. As shown in Supplementary Table 1 , compared with placebo in the fixed-effects model,
BTX-A $300 \mathrm{U}$ and $200 \mathrm{U}$ for NDO both showed significant declines in MDP (WMD: $-31.31,95 \%$ CI: -35.79 to $-26.84, I^{2}=0.0 \%, P=0.679$; WMD: $-33.01,95 \% \mathrm{CI}$ : -37.75 to $-28.27, I^{2}=0.0 \%, P=0.998$, respectively). However, there were no significant differences between BTX-A $300 \mathrm{U}$ and $200 \mathrm{U}$ for NDO (WMD: 1.16, 95\% CI: -3.29 to $5.60, I^{2}=0.0 \%, P=0.831$ ).

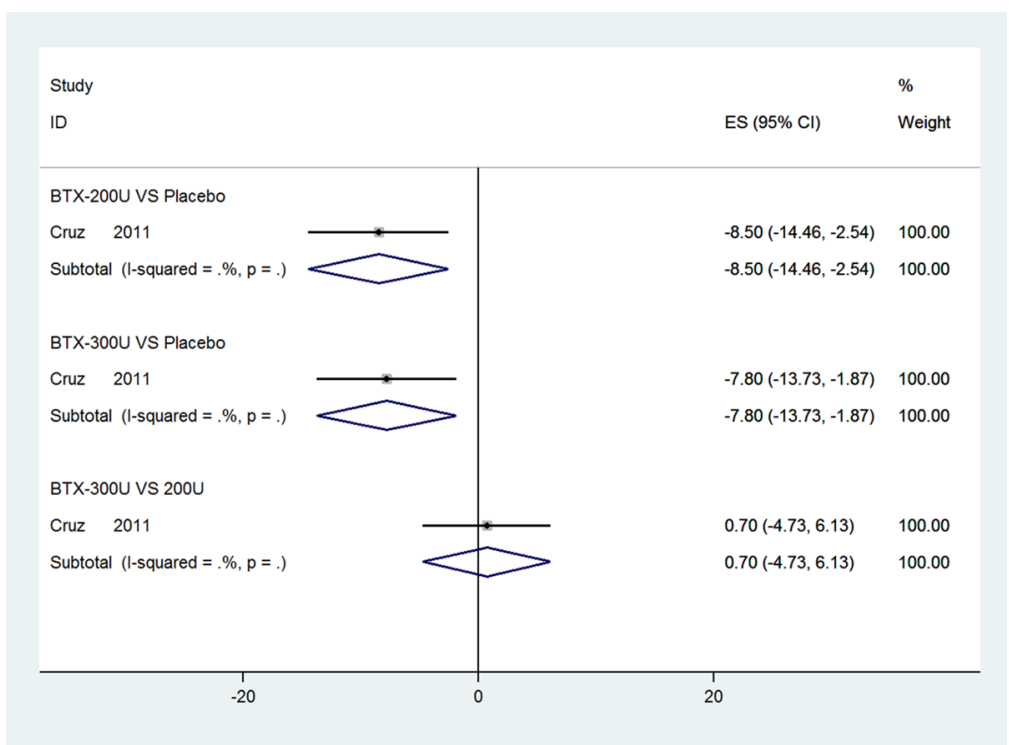

Figure 4: Forest plot of the changes of UI episodes per week of NDO at 12 weeks.

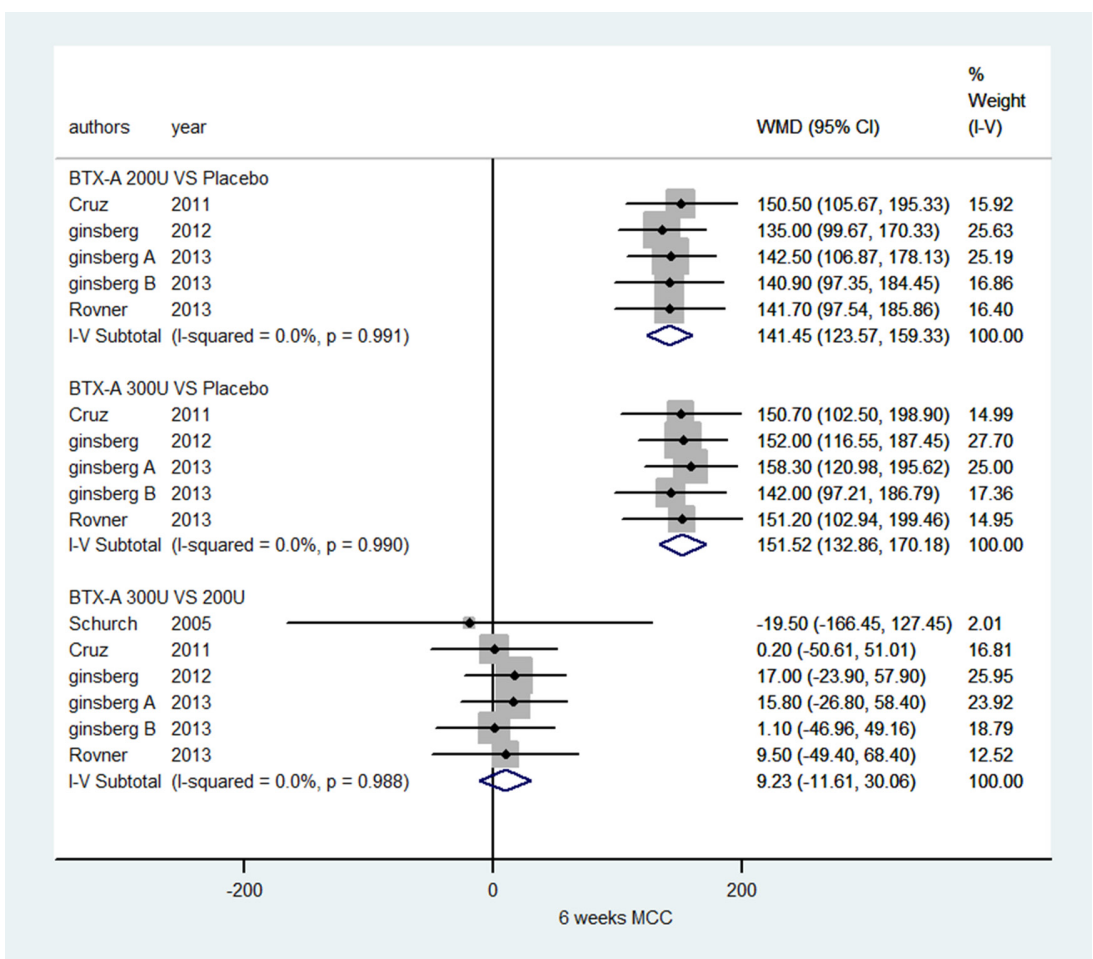

Figure 5: Forest plot of the changes of MCC of NDO at 6 weeks. 


\section{MDP of IDO based on short-term observation at 12} weeks

As shown in Supplementary Table 2, only one RCT [40] was available for MDP. Compared with placebo and results at 6 weeks, 5 different dosages showed no significant declines in MDP. Only 2 of 15 subgroups showed significant differences, i.e., BTX-A 150 U vs. 50 $\mathrm{U}$ and $200 \mathrm{U}$ vs. $150 \mathrm{U}$ for IDO (WMD: -8.90 , 95\% CI:
-16.98 to $-0.82, I^{2}=\mathrm{NA}, P=\mathrm{NA}$; WMD: $9.90,95 \% \mathrm{CI}$ : 1.03 to $18.77, I^{2}=\mathrm{NA}, P=\mathrm{NA}$, respectively).

\section{MDP of IDO based on short-term observation at 36 weeks}

Only one RCT [40] reported the effects of different dosages of BTX-A for IDO on MDP at 36 weeks. As shown in Supplementary Table 2, no dose of BTX-A demonstrated effectiveness in treatment of OAB compared with placebo.

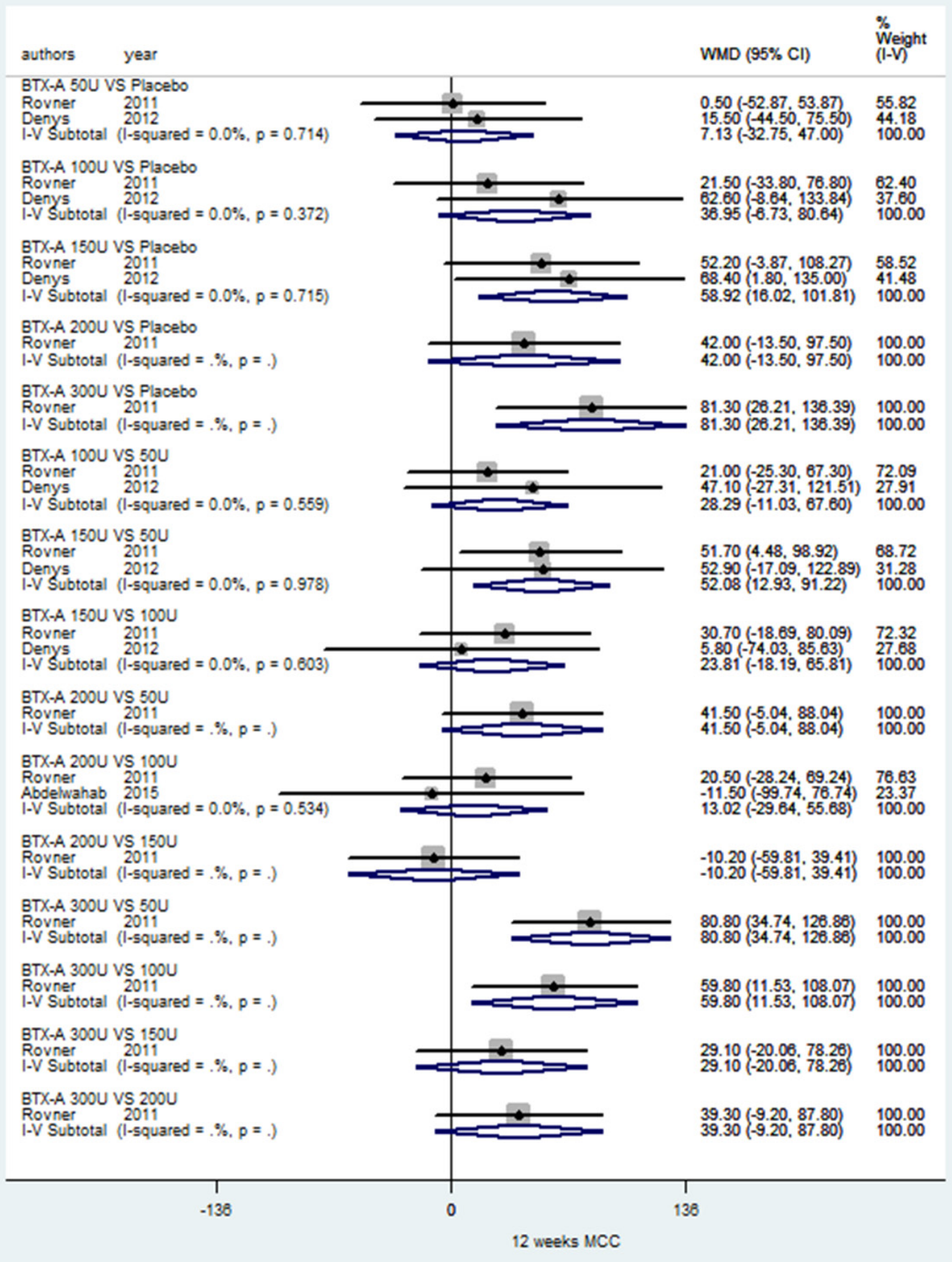

Figure 6: Forest plot of the changes of MCC of IDO at 12 weeks 


\section{Incontinence quality of life (I-QOL) of NDO at 6 weeks}

Three RCTs [36, 37, 41] were available for analysis of I-QOL at 6 weeks. As shown in Supplementary Table 1, both BTX-A $300 \mathrm{U}$ and $200 \mathrm{U}$ for NDO compared with placebo significantly improved the QOL (WMD: 22.10, $95 \%$ CI: 17.06 to $27.14, I^{2}=\mathrm{NA}, P=\mathrm{NA}$; WMD: 16.10 , $95 \%$ CI: 10.70 to $\left.21.50, I^{2}=\mathrm{NA}, P=\mathrm{NA}\right)$. However, there were no significant differences in improvement of I-QOL at 6 weeks between BTX-A $300 \mathrm{U}$ and $200 \mathrm{U}$ (WMD: $3.66,95 \%$ CI: -0.35 to $7.67, I^{2}=0.0 \%, P=0.605$ ).

\section{Safety}

Total adverse events were also reported in 6 studies [33-37, 39] that evaluated the safety of BTX-A injections for $\mathrm{OAB}$. Adverse events included urinary tract infections (UTI), urinary retention, hematuria, and muscle weakness, among others. The subgroup details are shown in Supplementary Tables 1 and 2. The results for $300 \mathrm{U}$ and $200 \mathrm{U}$ vs. placebo for NDO were significant and are clearly apparent in Supplementary Table 1 (BTX-A 300 U vs. placebo, relative risk (RR): $1.13,95 \% \mathrm{CI}: 1.07$ to 1.20 , $I^{2}=0.0 \%, P=0.897$; BTX-A 200 U vs. placebo, RR: 1.15 ,

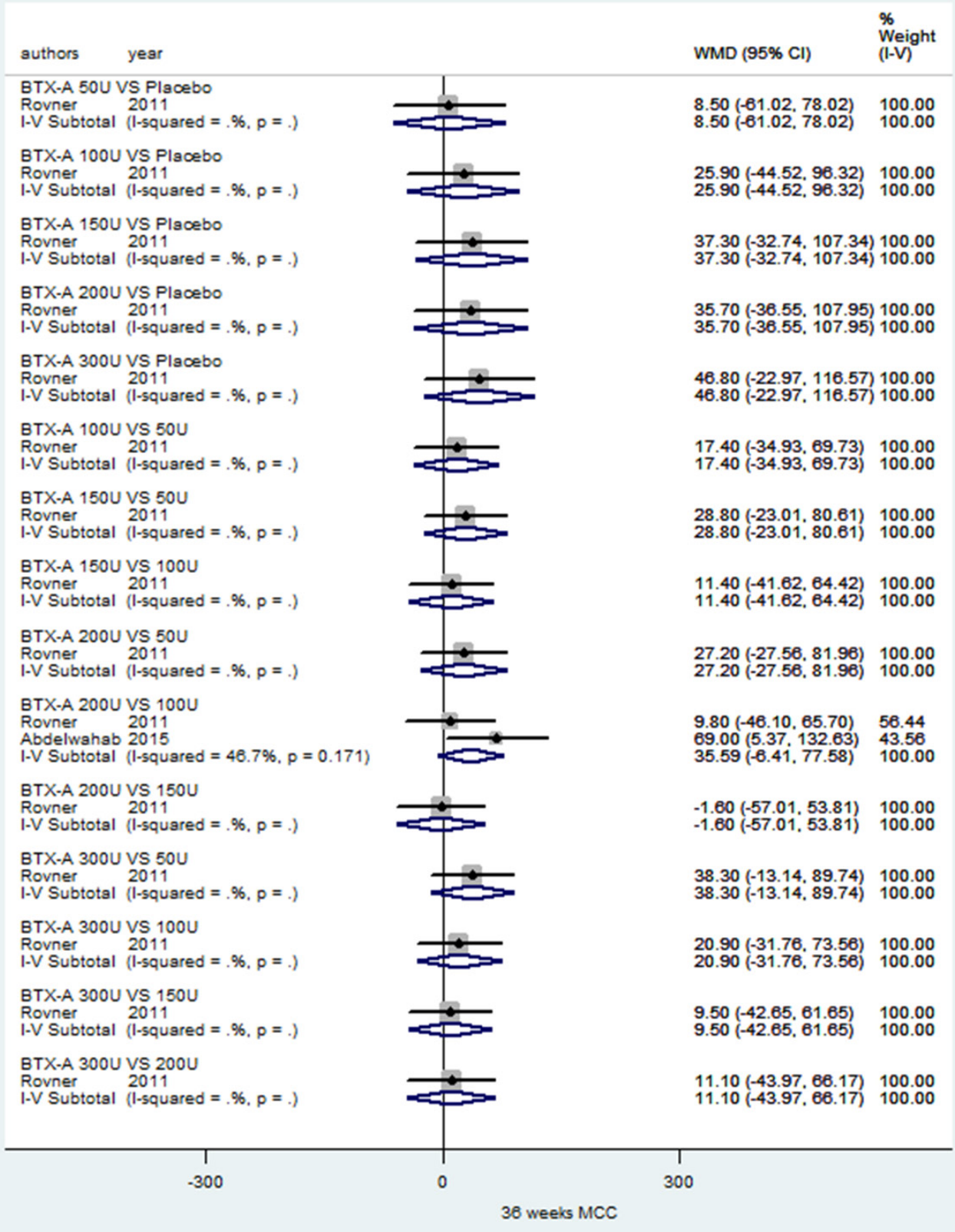

Figure 7: Forest plot of the changes of MCC of IDO at 36 weeks 
95\% CI: 1.09 to $\left.1.21, I^{2}=0.0 \%, P=0.988\right)$. However, significant differences were not observed between BTX-A 300U and 200U (RR: 0.99 , 95\% CI: 0.94 to $1.03, I^{2}=$ $0.0 \%, P=0.984)$. For IDO, as is shown in Supplementary Table 2, there were no significant differences in BTX-A 300U and 200U vs. placebo (BTX-A $300 \mathrm{U}$ vs. placebo, RR: $1.09,95 \%$ CI: 0.89 to $1.33, I^{2}=\mathrm{NA}, P=\mathrm{NA}$; BTX-A 200 U vs. placebo, RR: $1.10,95 \% \mathrm{CI}: 0.90$ to $1.35, I^{2}=$ NA, $P=$ NA) and other subgroups. These data indicated that therapy of NDO with BTX-A $300 \mathrm{U}$ and $200 \mathrm{U}$ leads to more complications than with placebo, while BTX-A for IDO have fewer complications.

\section{DISCUSSION}

$\mathrm{OAB}$ is a highly prevalent disease with a detrimental effect on patients, whose quality of life is greatly reduced due to the urinary incontinence caused by $\mathrm{OAB}$ [42]. Therefore, the treatment of OAB requires urgent attention. Although various treatment modalities including bladder and behavioral training, biofeedback, electrical stimulation, surgery, and pharmacotherapy $[21,43]$ have been used for OAB, the results have often been unsatisfactory. For example, anticholinergics are the current first-line pharmacotherapeutic agents indicated for $\mathrm{OAB}$, but no other effective medicines are available; however, these also have unwanted side effects, resulting in poor compliance and a suboptimal response [44, 45]. Hence, a new treatment is needed for OAB. BTX-A has been found to be suitable for both neurogenic and idiopathic incontinence $[46,47]$, and may also be useful for NDO and IDO.

BTX-A mainly inhibits the release of acetylcholine at nerve terminals and paralyzes the detrusor, thereby improving bladder conditions and reducing urinary symptoms [48]. Based on the theory that nerve terminals develop new acetylcholine-release sites and become functional over 3 to 9 months [49], and the fact that most RCTs repeated injections at more than 12 weeks after the first injection, we defined more than 12 weeks as longterm and not more than 12 weeks as short-term.

In this meta-analysis, the effectiveness and safety of 5 different dosages of BTX-A, including $50 \mathrm{U}, 100$ $\mathrm{U}, 150 \mathrm{U}, 200 \mathrm{U}$, and $300 \mathrm{U}$, as well as placebo, were analyzed. However, placebo and not all dosages were included and compared for analysis of each outcome indicator. This meta-analysis showed that BTX-A 300U and $200 \mathrm{U}$ significantly improved symptoms of NDO, while significant differences were not seen in BTX-A $300 \mathrm{U}$ and $200 \mathrm{U}$ for IDO, compared with placebo. Obvious efficacies were not seen in BTX-A 50U, 100U and $150 \mathrm{U}$ for IDO except for BTX-A $100 \mathrm{U}$ and $150 \mathrm{U}$ for the volume per void of IDO, compared with placebo. In addition, the efficacies of different dosages of BTX-A were not consistent in short- and long-term observations, and effect differences did not depend on the relationship between different doses for the same outcomes, as for UI episodes per week of NDO at 2 weeks and MCC of IDO at 12 weeks. BTX-A $300 \mathrm{U}$ and $200 \mathrm{U}$ had nearly the obvious effect on all outcomes for NDO in short-term observation ( 2 and 6 weeks), especially at 6 weeks. In addition, the results for outcomes including UI episodes per week, MCC, and MDP of NDO were consistent with those of other corresponding meta-analyses [15, 21]. Nevertheless, compared with placebo, there were no significant differences in effectiveness for MCC and MDP with BTX-A $300 \mathrm{U}$ and $200 \mathrm{U}$ for IDO at 36 weeks, and the changes in MDP showed no significant differences with BTX-A $300 \mathrm{U}$ and $200 \mathrm{U}$ for IDO at 12 weeks, which may be the result of BTX-A wash-out and targeted areas of BTX-A for NDO and IDO are different or other factors resulting in IDO interfere with the effect of BTX-A. Additionally, BTX-A $300 \mathrm{U}$ and $200 \mathrm{U}$ still remained effective for UI episodes per week at 12 weeks. Compared with placebo, it seemed unusual that BTX-A $200 \mathrm{U}$ showed no significant improvement in MCC of IDO, while BTX-A $150 \mathrm{U}$ and $300 \mathrm{U}$ had opposite effects at 12 weeks; these findings were not consistent with the results of the meta-analysis by Sun et al. [19], in which the same data were used for different dosages in assessing MCC of IDO. This may be the result of small sample sizes and fewer studies included for MCC of IDO in this metaanalysis. Chapple et al [50] reported that treatment with BTX-A 100 U provided both statistically significant and clinically relevant improvements in all OAB symptoms. This meta-analysis also revealed that doses of $100 \mathrm{U}$ and $150 \mathrm{U}$ were significantly effective in increasing volume per void of IDO at 12 weeks and doses of 200U and $300 \mathrm{U}$ were significantly effective in increasing volume per void of IDO at 12 weeks. To better examine longterm effectiveness and drug tolerance, the outcomes of repeated BTX-A injections were also included for analysis; the results showed that significant improvements in UI episodes per week, MCC, and I-QOL of NDO were present at 6 weeks. Kennelly et al [37] focused on the results of repeated treatment for up to five cycles. Due to all included studies were only survey about UI episodes per week in patients with NDO, weren't the UI episodes per week in patients with IDO. These meta-analyses can't survey research the outcome for UI episodes per week in patients with IDO.

Almost all previous systematic reviews and metaanalyses reported adverse reactions such as UTIs, urinary retention, hematuria, and muscle weakness. Therefore, individual adverse reaction was not analyzed in this metaanalysis. However, the total adverse events including urinary retention, hematuria, and muscle weakness, among others were not reported in previous meta-analysis [15-17, 19-21]. Hence, the total adverse events were analyzed to evaluate the safety of BTX-A for NDO and OAB. We found that BTX-A $300 \mathrm{U}$ and $200 \mathrm{U}$ for NDO had slightly more adverse events than placebo, and for IDO had fewer 
adverse events. In addition, dosages less than 200U of BTX-A for IDO also had fewer adverse events. However, treatment with BTX-A was well-tolerated and adverse effects were mainly limited to localized urologic events including UTIs, urinary retention and hematuria, which were easily treated and managed. Other adverse effects were also well-tolerated.

The highlights of this meta-analysis are as follows. First, different doses of BTX-A were evaluated, and the effectiveness of BTX-A was assessed for multiple outcomes including symptoms, bladder function, and incontinence quality of life (I-QOL). Second, we comprehensively and systematically evaluated the effectiveness of BTX-A for two types of OAB including NDO and IDO from two observation periods, and also focused on the safety of BTX-A, thereby reducing the risk of errors from correct outcomes. Furthermore, subgroup analyses of dosages and types of OAB were performed to substitute for pooled dosages or comparisons of grouped dosages from different studies, to objectively reflect true effectiveness and safety, and to guide clinicians to treat two kinds of OAB. However, there are also several limitations which should be discussed in our meta-analysis. First, only 11 RCTs with insufficient numbers of patients were included in our meta-analysis, which may influence our conclusions. Second, benign prostatic hyperplasia (BPH) is a prominent disease in males. Although the pathogenesis of $\mathrm{OAB}$ in males and females is different, subgroup analyses for pathogenesis were not performed in this meta-analysis. With few RCTs and lack of relevant data, more studies are needed to investigate male and female differences. Third, although this meta-analysis assessed the effectiveness of BTX-A from two observation periods, the short- and long-term observations were insufficient. Therefore, short- and long-term observations and the use of repeated injections require further investigations. In addition, more high-quality RCTs with larger sample sizes should be performed, and a subsequent updated metaanalysis will be necessary for in-depth and comprehensive assessment of the safety and efficiency of BTX-A.

\section{MATERIALS AND METHODS}

This meta-analysis was conducted according to the Preferred Reporting Items for Systematic Reviews and Meta-analyses (PRISMA) statement [51]. No ethical issues were involved in this study, and all collected data were based on published studies.

\section{Search strategy}

The MEDLINE, EMBASE, and Cochrane Controlled Trials Register databases were searched through November 3, 2016 to identify relevant articles that evaluated the effectiveness and safety of BTX-A for treatment of $\mathrm{OAB}$. We also searched the reference lists of the retrieved studies. The search keywords were as follows: "urinary bladder", "overactive bladder", "overactive detrusor", "overactive detrusor function", "detrusor overactive", "urinary incontinence", "botulinum toxin", "Clostridium botulinum", "onabotulinumtoxin", "abobotulinumtoxin", and "BOTOX".

\section{Inclusion and exclusion criteria and trial selection}

RCTs were included for meta-analysis if the following criteria were met: (1) all patients were diagnosed with urinary incontinence due to $\mathrm{OAB},(2)$ the study population was over 18 years old, (3) the studies compared BTX-A with placebo or different dosages of BTX-A, and (4) the language was limited to English.

Articles were excluded for the following reasons: (1) patients had stress incontinence, (2) the study was a duplicate, (3) the data could not be extracted or obtained through contact with the author, or (4) insufficient information was available to calculate missing standard deviations (SD) for continuous outcomes.

\section{Quality assessment}

The quality of the studies was assessed according to random sequence generation, allocation concealment, blinding of participants and personnel, blinding of outcome assessment, incomplete outcome data, and selective reporting and other biases. In accordance with the Cochrane Handbook for Systematic Reviews of Interventions v.5.1.0 [52], and based on the quality assessment criteria, each study was rated and assigned to one of the three following categories: if all quality criteria were adequately met, the study was deemed to have a low risk of bias; if one or more quality criteria were unclear, the study was deemed to have an unclear risk of bias; if one or more of the criteria was not met or not included, the study was deemed to have a high risk of bias. Differences were discussed among the authors.

\section{Data collection}

We carefully reviewed the titles, abstracts, and the full texts of the articles. The following information in each study was collected for our meta-analysis: (1) basic information of the study and patients: the author, year, sample size, and design of each study; the gender, ages, type of urinary incontinence, and basic disease; (2) method: the details of the treatment group and the control group of each study; (3) outcome: UI episodes per week as the primary outcome, and urodynamic parameters including MCC, MDP, and the volume per void as the secondary outcomes; the I-QOL of patients and the total adverse events. The time points of study outcomes were approximately divided into two periods, based on Frenkl's 
study [49]. We defined time points as follows: not more than 12 weeks, short-term observation; more than 12 weeks, long-term observation. Data for single cycle injections and repeated injections were collected for this meta-analysis.

All data were independently collected by two reviewers. Disagreements on the extracted data were resolved by discussion and consultation with an expert.

\section{Statistical analysis}

This meta-analysis was performed using Stata 12.0. Dichotomous and continuous outcomes were expressed as relative risk (RR) with $95 \%$ confidence interval (CI) $[52,53]$, and weighted mean difference (WMD) [52] with $95 \% \mathrm{CI}$, at a significance level of $P<0.05$, respectively. Heterogeneity [54] between studies was also evaluated and measured using chi-square tests, at a significance level of $P<0.1 . I^{2}=0$ indicates no heterogeneity and larger values of $I^{2}$ represent greater heterogeneity. When $I^{2}>50 \%$, studies were considered to have significant heterogeneity; we then used a random-effects model to conduct the meta-analysis. For $I^{2}<50 \%$, a fixed-effects model was used [52]. Because dosages and the types of $\mathrm{OAB}$ were causes of heterogeneity, subgroup analysis for dosages and types of OAB including IDO and NDO was performed.

\section{CONCLUSIONS}

This meta-analysis suggests that BTX-A $300 \mathrm{U}$ and 200U have significant efficacies for NDO for shortterm treatments, while obvious efficacies were not seen in BTX-A $300 \mathrm{U}$ and $200 \mathrm{U}$ for IDO for long-term treatments. Obvious efficacies were also not seen in BTX-A $50 \mathrm{U}, 100 \mathrm{U}$ and $150 \mathrm{U}$ for IDO except for BTX-A $100 \mathrm{U}$ and $150 \mathrm{U}$ for the volume per void of IDO at 12 weeks. In addition, the treatments of BTX-A were with minimal, local, and manageable adverse effects. Hence, BTX-A $200 \mathrm{U}$ is recommended for management of NDO for short-term treatment for there was no significant difference from the larger dose of $300 \mathrm{U}$. The short-term efficacies of BTX-A for IDO remain to be investigated.

\section{Ethical approval}

Not needed.

\section{Author contributions}

$\mathrm{CZ}$ and YMN had full access to all of the data in the study, and take responsibility for the integrity of the data and the accuracy of the data analysis. HYG, JKS and JX designed the study. JX, WJZ and QSY developed and tested the data collection forms. QSY and WJZ acquired the data. CZ and HYG conducted the analysis and interpreted the data. YMN and $\mathrm{CZ}$ drafted the manuscript. All authors critically revised the manuscript. $\mathrm{CZ}$ and $\mathrm{YMN}$ had guarantor.

\section{ACKNOWLEDGMENTS}

This study was supported by the Foundations of the Science and Technology Department of Hubei Province (No. 2016CFB567) and Hubei Province health and family planning scientific research project (No. WJ2017F069). The funders had no roles in study design, data collection and analysis, decision to publish, or preparation of the manuscript.

\section{CONFLICTS OF INTEREST}

The author(s) of this work have nothing to disclose.

\section{FUNDING}

This study was supported by the Foundations of the Science and Technology Department of Hubei Province (No. 2016CFB567) and Hubei Province health and family planning scientific research project (No. WJ2017F069).

\section{REFERENCES}

1. Abrams P, Cardozo L, Fall M, Griffiths D, Rosier P, Ulmsten U, van Kerrebroeck P, Victor A, Wein A. The standardisation of terminology of lower urinary tract function: report from the Standardisation Sub-committee of the International Continence Society. Am J Obstet Gynecol. 2002; 187:116-126.

2. Stewart WF, Van Rooyen JB, Cundiff GW, Abrams P, Herzog AR, Corey R, Hunt TL, Wein AJ. Prevalence and burden of overactive bladder in the United States. World J Urol. 2003; 20:327-336.

3. Sacco E, Tienforti D, D'Addessi A, Pinto F, Racioppi M, Totaro A, D'Agostino D, Marangi F, Bassi P. Social, economic, and health utility considerations in the treatment of overactive bladder. Open Access J Urol. 2010; 2:11-24.

4. Chancellor MB, Patel V, Leng WW, Shenot PJ, Lam W, Globe DR, Loeb AL, Chapple CR. OnabotulinumtoxinA improves quality of life in patients with neurogenic detrusor overactivity. Neurology. 2013; 81:841-848.

5. Hollingworth W, Campbell JD, Kowalski J, Ravelo A, Girod I, Briggs A, Sullivan SD. Exploring the impact of changes in neurogenic urinary incontinence frequency and condition-specific quality of life on preference-based outcomes. Qual Life Res. 2010; 19:323-331.

6. Lee JS, Koo BI, Shin MJ, Chang JH, Kim SY, Ko HY. Differences in urodynamic variables for vesicoureteral reflux depending on the neurogenic bladder type. Ann Rehabil Med. 2014; 38:347-352. 
7. Garely AD, Burrows LJ. Current pharmacotherapeutic strategies for overactive bladder. Expert Opin Pharmacother. 2002; 3:827-833.

8. Asimakopoulos AD, Cerruto MA, Del Popolo G, La Martina M, Artibani W, Carone R, Finazzi-Agro E. An overview on mixed action drugs for the treatment of overactive bladder and detrusor overactivity. Urol Int. 2012; 89:259-269.

9. Jundt K, Schreyer K, Friese K, Peschers U. Anticholinergic therapy: do the patients take the pills prescribed? Arch Gynecol Obstet. 2011; 284:663-666.

10. Dong M, Yeh F, Tepp WH, Dean C, Johnson EA, Janz R, Chapman ER. SV2 is the protein receptor for botulinum neurotoxin A. Science. 2006; 312:592-596.

11. Simpson LL. Kinetic studies on the interaction between botulinum toxin type A and the cholinergic neuromuscular junction. J Pharmacol Exp Ther. 1980; 212:16-21.

12. Schurch B, Schmid DM, Stohrer M. Treatment of neurogenic incontinence with botulinum toxin A. N Engl J Med. 2000; 342:665.

13. Smith CP, Boone TB, de Groat WC, Chancellor MB, Somogyi GT. Effect of stimulation intensity and botulinum toxin isoform on rat bladder strip contractions. Brain Res Bull. 2003; 61:165-171.

14. Apostolidis A, Dasgupta P, Denys P, Elneil S, Fowler CJ, Giannantoni A, Karsenty G, Schulte-Baukloh H, Schurch B, Wyndaele JJ. Recommendations on the use of botulinum toxin in the treatment of lower urinary tract disorders and pelvic floor dysfunctions: a European consensus report. Eur Urol. 2009; 55:100-119.

15. Cheng T, Shuang WB, Jia DD, Zhang M, Tong XN, Yang WD, Jia XM, Li S. Efficacy and Safety of OnabotulinumtoxinA in Patients with Neurogenic Detrusor Overactivity: A Systematic Review and Meta-Analysis of Randomized Controlled Trials. PLoS One. 2016; 11:e0159307.

16. Cui Y, Wang L, Liu L, Zeng F, Niu J, Qi L, Chen H. Botulinum toxin-A injections for idiopathic overactive bladder: a systematic review and meta-analysis. Urol Int. 2013; 91:429-438.

17. Cui Y, Zhou X, Zong H, Yan H, Zhang Y. The efficacy and safety of onabotulinumtoxinA in treating idiopathic OAB: A systematic review and meta-analysis. Neurourol Urodyn. 2015; 34:413-419.

18. Mehta S, Hill D, McIntyre A, Foley N, Hsieh J, Ethans K, Teasell RW, Loh E, Welk B, Wolfe D. Meta-analysis of botulinum toxin A detrusor injections in the treatment of neurogenic detrusor overactivity after spinal cord injury. Arch Phys Med Rehabil. 2013; 94:1473-1481.

19. Sun Y, Luo D, Tang C, Yang L, Shen H. The safety and efficiency of onabotulinumtoxinA for the treatment of overactive bladder: a systematic review and meta-analysis. Int Urol Nephrol. 2015; 47:1779-1788.

20. Zhang $\mathrm{R}, \mathrm{Xu} \mathrm{Y}$, Yang S, Liang $\mathrm{H}$, Zhang Y, Liu Y. OnabotulinumtoxinA for neurogenic detrusor overactivity and dose differences: a systematic review. Int Braz J Urol. 2015; 41:207-219.
21. Zhou X, Yan HL, Cui YS, Zong HT, Zhang Y. Efficacy and safety of onabotulinumtoxinA in treating neurogenic detrusor overactivity: a systematic review and metaanalysis. Chin Med J (Engl). 2015; 128:963-968.

22. Denys P, Le Normand L, Ghout I, Costa P, ChartierKastler E, Grise P, Hermieu JF, Amarenco G, Karsenty G, Saussine C, Barbot F. Efficacy and safety of low doses of onabotulinumtoxinA for the treatment of refractory idiopathic overactive bladder: a multicentre, double-blind, randomised, placebo-controlled dose-ranging study. Eur Urol. 2012; 61:520-529.

23. Schulte-Baukloh H, Weiss C, Stolze T, Herholz J, Sturzebecher B, Miller K, Knispel HH. Botulinum-A toxin detrusor and sphincter injection in treatment of overactive bladder syndrome: objective outcome and patient satisfaction. Eur Urol. 2005; 48:984-990; discussion 990.

24. Schmid DM, Sauermann P, Werner M, Schuessler B, Blick N, Muentener M, Strebel RT, Perucchini D, Scheiner D, Schaer G, John H, Reitz A, Hauri D, et al. Experience with 100 cases treated with botulinum-A toxin injections in the detrusor muscle for idiopathic overactive bladder syndrome refractory to anticholinergics. J Urol. 2006; 176:177-185.

25. Rajkumar GN, Small DR, Mustafa AW, Conn G. A prospective study to evaluate the safety, tolerability, efficacy and durability of response of intravesical injection of botulinum toxin type A into detrusor muscle in patients with refractory idiopathic detrusor overactivity. BJU Int. 2005; 96:848-852.

26. Popat R, Apostolidis A, Kalsi V, Gonzales G, Fowler CJ, Dasgupta P. A comparison between the response of patients with idiopathic detrusor overactivity and neurogenic detrusor overactivity to the first intradetrusor injection of botulinum-A toxin. J Urol. 2005; 174:984-989.

27. Kuo HC. Clinical effects of suburothelial injection of botulinum A toxin on patients with nonneurogenic detrusor overactivity refractory to anticholinergics. Urology. 2005; 66:94-98.

28. Kessler TM, Danuser H, Schumacher M, Studer UE, Burkhard FC. Botulinum A toxin injections into the detrusor: an effective treatment in idiopathic and neurogenic detrusor overactivity? Neurourol Urodyn. 2005; 24:231-236.

29. Flynn MK, Webster GD, Amundsen CL. The effect of botulinum-A toxin on patients with severe urge urinary incontinence. J Urol. 2004; 172:2316-2320.

30. Sahai A, Khan MS, Dasgupta P. Efficacy of botulinum toxin-A for treating idiopathic detrusor overactivity: results from a single center, randomized, double-blind, placebo controlled trial. J Urol. 2007; 177:2231-2236.

31. Flynn MK, Amundsen CL, Perevich M, Liu F, Webster GD. Outcome of a randomized, double-blind, placebo controlled trial of botulinum A toxin for refractory overactive bladder. J Urol. 2009; 181:2608-2615.

32. Abdelwahab O, Sherif H, Soliman T, Elbarky I, Eshazly A. Efficacy of botulinum toxin type A 100 Units versus 200 units for treatment of refractory idiopathic overactive bladder. Int Braz J Urol. 2015; 41:1132-1140. 
33. Cruz F, Herschorn S, Aliotta P, Brin M, Thompson C, Lam W, Daniell G, Heesakkers J, Haag-Molkenteller C. Efficacy and safety of onabotulinumtoxinA in patients with urinary incontinence due to neurogenic detrusor overactivity: a randomised, double-blind, placebo-controlled trial. Eur Urol. 2011; 60:742-750.

34. Dmochowski R, Chapple C, Nitti VW, Chancellor M, Everaert K, Thompson C, Daniell G, Zhou J, HaagMolkenteller C. Efficacy and safety of onabotulinumtoxinA for idiopathic overactive bladder: a double-blind, placebo controlled, randomized, dose ranging trial. J Urol. 2010; 184:2416-2422.

35. Ginsberg D, Cruz F, Herschorn S, Gousse A, Keppenne V, Aliotta P, Sievert KD, Brin MF, Jenkins B, Thompson C, Lam W, Heesakkers J, Haag-Molkenteller C. OnabotulinumtoxinA is effective in patients with urinary incontinence due to neurogenic detrusor overactivity [corrected] regardless of concomitant anticholinergic use or neurologic etiology. Adv Ther. 2013; 30:819-833.

36. Ginsberg D, Gousse A, Keppenne V, Sievert KD, Thompson C, Lam W, Brin MF, Jenkins B, Haag-Molkenteller C. Phase 3 efficacy and tolerability study of onabotulinumtoxinA for urinary incontinence from neurogenic detrusor overactivity. J Urol. 2012; 187:2131-2139.

37. Kennelly M, Dmochowski R, Ethans K, Karsenty G, Schulte-Baukloh H, Jenkins B, Thompson C, Li D, Haag-Molkenteller C. Long-term efficacy and safety of onabotulinumtoxinA in patients with urinary incontinence due to neurogenic detrusor overactivity: an interim analysis. Urology. 2013; 81:491-497.

38. Nitti VW, Dmochowski R, Herschorn S, Sand P, Thompson C, Nardo C, Yan X, Haag-Molkenteller C. OnabotulinumtoxinA for the treatment of patients with overactive bladder and urinary incontinence: results of a phase 3, randomized, placebo controlled trial. J Urol. 2013; 189:2186-2193.

39. Rovner E, Dmochowski R, Chapple C, Thompson C, Lam W, Haag-Molkenteller C. OnabotulinumtoxinA improves urodynamic outcomes in patients with neurogenic detrusor overactivity. Neurourol Urodyn. 2013; 32:1109-1115.

40. Rovner E, Kennelly M, Schulte-Baukloh H, Zhou J, Haag-Molkenteller C, Dasgupta P. Urodynamic results and clinical outcomes with intradetrusor injections of onabotulinumtoxinA in a randomized, placebo-controlled dose-finding study in idiopathic overactive bladder. Neurourol Urodyn. 2011; 30:556-562.

41. Schurch B, de Seze M, Denys P, Chartier-Kastler E, Haab F, Everaert K, Plante P, Perrouin-Verbe B, Kumar C, Fraczek $\mathrm{S}$, Brin MF. Botulinum toxin type a is a safe and effective treatment for neurogenic urinary incontinence: results of a single treatment, randomized, placebo controlled 6-month study. J Urol. 2005; 174:196-200.
42. Sievert KD, Chapple C, Herschorn S, Joshi M, Zhou J, Nardo C, Nitti VW. OnabotulinumtoxinA $100 \mathrm{U}$ provides significant improvements in overactive bladder symptoms in patients with urinary incontinence regardless of the number of anticholinergic therapies used or reason for inadequate management of overactive bladder. Int J Clin Pract. 2014; 68:1246-1256.

43. Engeler DS, Meyer D, Abt D, Muller S, Schmid HP. Sacral neuromodulation for the treatment of neurogenic lower urinary tract dysfunction caused by multiple sclerosis: a single-centre prospective series. BMC Urol. 2015; 15:105.

44. Chapple CR, Khullar V, Gabriel Z, Muston D, Bitoun CE, Weinstein D. The effects of antimuscarinic treatments in overactive bladder: an update of a systematic review and meta-analysis. Eur Urol. 2008; 54:543-562.

45. Krhut J, Gartner M, Petzel M, Sykora R, Nemec D, Tvrdik J, Skoupa J. Persistence with first line anticholinergic medication in treatment-naive overactive bladder patients. Scand J Urol. 2014; 48:79-83.

46. Anger JT, Weinberg A, Suttorp MJ, Litwin MS, Shekelle PG. Outcomes of intravesical botulinum toxin for idiopathic overactive bladder symptoms: a systematic review of the literature. J Urol. 2010; 183:2258-2264.

47. Dmochowski R, Sand PK. Botulinum toxin A in the overactive bladder: current status and future directions. BJU Int. 2007; 99:247-262.

48. Dolly JO, O'Connell MA. Neurotherapeutics to inhibit exocytosis from sensory neurons for the control of chronic pain. Curr Opin Pharmacol. 2012; 12:100-108.

49. Frenkl TL, Rackley RR. Injectable neuromodulatory agents: botulinum toxin therapy. Urol Clin North Am. 2005; 32:89-99.

50. Chapple C, Sievert KD, MacDiarmid S, Khullar V, Radziszewski P, Nardo C, Thompson C, Zhou J, HaagMolkenteller C. OnabotulinumtoxinA 100 U significantly improves all idiopathic overactive bladder symptoms and quality of life in patients with overactive bladder and urinary incontinence: a randomised, double-blind, placebocontrolled trial. Eur Urol. 2013; 64:249-256.

51. Moher D, Liberati A, Tetzlaff J, Altman DG. Preferred reporting items for systematic reviews and meta-analyses: the PRISMA statement. Journal of clinical epidemiology. 2009; 62:1006-1012.

52. Higgins JP. Cochrane handbook for systematic reviews of interventions, v.5.1. Available from: http://www. cochrane-handbook.org. [Last updated on 2011 Mar 05]. 2011.

53. Deeks J. Issues in the selection of a summary statistic for meta-analysis of clinical trials with binary outcomes. Stat Med. 2002; 21:1575-1600.

54. Higgins JP. Quantifying heterogeneity in a meta-analysis. Stat Med. 2002; 21:1539-1558. 